Technical Note

\title{
Single-calibrant quantification of seized synthetic opioids by liquid chromatography-chemiluminescence nitrogen detection
}

\author{
Ilpo Rasanen ${ }^{\mathrm{a}}$, Marianne Kyber ${ }^{\mathrm{b}}$, Ilmari Szilvay ${ }^{\mathrm{b}}$, Janne Rintatalo ${ }^{\mathrm{c}}$, Ilkka Ojanperäa,d,* \\ a National Institute for Health and Welfare, Forensic Toxicology Unit, PO Box 30, FI-00271 Helsinki, Finland \\ ${ }^{\mathrm{b}}$ Finnish Customs Laboratory, PO Box 53, FI-02151 Espoo, Finland

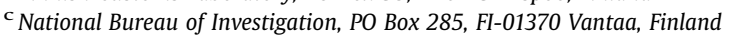 \\ d University of Helsinki, Department of Forensic Medicine, PO Box 40, FI-00014 University of Helsinki, Finland
}

\section{A R T I C L E I N F O}

\section{Article history:}

Received 12 August 2019

Received in revised form 6 October 2019

Accepted 20 October 2019

Available online 22 October 2019

\section{Keywords:}

New psychoactive substances

Drug seizure

Fentanyl derivative

Furanylfentanyl

Chemiluminescence nitrogen detection

Reference standard

\begin{abstract}
A B S T R A C T
Drug seizures involving a wide variety of emerging new psychoactive substances (NPS) call for new approaches for instant quantification and valuation. Liquid chromatography-chemiluminescence nitrogen detection (LC-CLND) was used in the quantification of opioids with a single secondary standard (caffeine), utilizing the detector's equimolar response to nitrogen. The mean $N$-equimolarity of CLND for ten fentanyl derivatives and U-47700 by the present LC-CLND method was $96.4 \%$ (range 91101\%). The furanylfentanyl samples consisted of 112 powdery samples with a mean (median, range) hydrochloride purity of $13 \%(4.9 \%, 0.08-100 \%)$. The purity distribution of the furanylfentanyl samples was distinctly bipartite, showing only lower than $9 \%(\mathrm{~N}=98)$ and higher than $60 \%(\mathrm{~N}=14)$ purities. The carfentanil samples consisted of eight brownish sticky samples with a mean (median, range) hydrochloride purity of $0.064 \%(0.063 \%, 0.052-0.092 \%)$. The U-47700 samples consisted of seven powdery samples with a mean (median, range) hydrochloride purity of $89.0 \%(100 \%, 51-100 \%)$. The present application to synthetic opioid analysis widens the scope of the established LC-CLND method, previously found useful for single-calibrant quantification of stimulant/hallucinogenic and cannabinoid type of NPS.
\end{abstract}

(C) 2019 Elsevier B.V. All rights reserved.

\section{Introduction}

Opioids are essential in the medical treatment of severe pain but they are also largely abused by drug addicts. During the recent years, the illicit drugs scene has been shaken by the emergence of various fentanyl derivatives and other potent opioids onto the stage of new psychoactive substances (NPS) [1,2]. As the fentanyl structure is exceptionally prone to be modified, the number of different derivatives with pharmacological activity is high. It has been estimated that out of approximately 1400 fentanyl analogues, more than 200 compounds have been described in the literature [3].

The diversity and rapid turnover of NPS makes their analysis challenging, as high-quality reference standards are not readily accessible. While unequivocal identification of seized samples can be carried out by a combination of high resolution mass spectrometry and NMR spectroscopy, the purity estimation in the absence of

\footnotetext{
* Corresponding author at: National Institute for Health and Welfare, Forensic Toxicology Unit, PO Box 30, FI-00271 Helsinki, Finland.

E-mail address: ilkka.ojanpera@helsinki.fi (I. Ojanperä).
}

reference standards requires a technique with universal or predictable response as opposed to mass spectrometry. In our earlier papers, we have studied liquid chromatography-chemiluminescence nitrogen detection (LC-CLND) in the quantification of NPS with a single secondary standard (caffeine), utilizing the detector's equimolar response to nitrogen [4,5]. The developed method enabled analysis of phenethylamines, cathinones and tryptamines, as well as to nitrogen containing synthetic cannabinoids, at a level of uncertainty of measurement $(<20 \%)$ comparable to conventional quantification methods [5].

Here, using essentially the same conditions for sample preparation and LC-CLND analysis as in the previous paper [5], we focus on the quantification of fentanyl derivatives and report purity values for seized samples of furanylfentanyl, carfentanil and U-47700.

\section{Materials and methods}

\subsection{Materials}

Seized material with previously positively identified main components was obtained through the National Bureau of 
Investigation and from the Finnish Customs Laboratory for quantitative analysis by LC-CLND.

The secondary reference standard used for quantification by LC-CLND was caffeine (Sigma-Aldrich C1778, purity 98.9\%).

Certified reference standards were used to determine the equimolarity of the CLND detector. Standards were selected according to their availability to the laboratory. Fentanyl solution (99.9\%) $1.0 \mathrm{mg} / \mathrm{mL}$ in methanol was from LGC GmbH (Luckenwalde, Germany), para-fluorofentanyl $\mathrm{HCl}$ (>95\%) and furanylfentanyl $\mathrm{HCl}$ (98.9\%) were from Cayman Chemical (Ann Arbor, MI, USA), $\mathrm{U}-47700 \mathrm{HCl}(92.8 \pm 0.5 \%)$ was from Chiron (Trondheim, Norway), alpha-methylfentanyl $\mathrm{HCl}$ (98\%) was from Toronto Research Chemical Inc (North York, ON, Canada), cis-3-methylfentanyl $\mathrm{HCl}$ (99.6\%), trans-3-methylfentanyl $\mathrm{HCl}$ (98.7\%) and norfentanyl $\mathrm{HCl}$ hydrate (99.9\%) were from Lipomed (Arlesheim, Switzerland), carfentanil citrate was from United Nations Narcotics Lab (Vienna, Austria), remifentanil $\mathrm{HCl}$ (99.5\%) was from GlaxoSmithKline (Durham, UK) and sufentanil citrate (99.6\%) was from Janssen Pharmaceutica N.V. (Beerse, Belgium).

\subsection{Apparatus}

LC-CLND analysis was performed with an Agilent Technologies (Santa Clara, CA, USA) 1100 series liquid chromatograph equipped with an autosampler, binary pump, column oven, 1260 Infinity degasser, and 1260 Infinity UV diode array detector (DAD). Chromatographic separation was performed with a Phenomenex (Torrance, CA, USA) Luna PFP(2) $100 \times 2 \mathrm{~mm}(3 \mu \mathrm{m})$ column and a $4 \times 2 \mathrm{~mm}$ PFP precolumn. The nitrogen-specific detector was an Antek (PAC, Houston, TX, USA) 8060 CLND, coupled online after the $\mathrm{DAD}$. The detector was interfaced with the computer using an Agilent 35900E analog-to-digital converter.

\subsection{Sample preparation}

General procedure: a quantity of $10-20 \mathrm{mg}$ of the seized material was dissolved in $0.1 \%$ formic acid (FA): methanol (MeOH) $9: 1 \mathrm{v} / \mathrm{v}$ to obtain a solution of $10 \mathrm{mg} / \mathrm{mL}$ of seized material. This solution was analyzed directly in case of low-content samples or diluted proportionally to obtain a solution of $1.0 \mathrm{mg} / \mathrm{mL}$ of seized material for LC-CLND analysis.

For some high-content samples, a solution of $1.0 \mathrm{mg} / \mathrm{mL}$ was prepared in $\mathrm{MeOH}$ and diluted with $0.1 \% \mathrm{FA}$ to obtain a solution of $0.10 \mathrm{mg} / \mathrm{mL}$ of seized material. In all cases, sample preparation was carried out to obtain an analyte concentration corresponding to approximately $20-80 \mathrm{ng}$ of nitrogen per injection.

\subsection{LC-CLND analysis}

LC separation was performed in gradient mode at $40^{\circ} \mathrm{C}$. The mobile phase components were $0.1 \%$ FA and methanol. Flow rate was $0.25 \mathrm{~mL} / \mathrm{min}$ and injection volume $10 \mu \mathrm{L}$. The proportion of methanol was increased from $10 \%$ to $90 \%$ over 15 min and held at $90 \%$ for $5 \mathrm{~min}$. Post-time was $10 \mathrm{~min}$. The DAD signal was recorded at $230 \mathrm{~nm}$ and peak controlled spectra were recorded at 210-400 $\mathrm{nm}$. Although the compounds were pre-identified by other methods, the DAD signal was used to confirm the peak purity by means of the Agilent ChemStation similarity factor algorithm.

For CLND analysis, the inlet oxygen flow was $250 \mathrm{~mL} / \mathrm{min}$, helium flow $50 \mathrm{~mL} / \mathrm{min}$, and make-up helium flow $50 \mathrm{~mL} / \mathrm{min}$. The ozone generator oxygen flow was $25 \mathrm{~mL} / \mathrm{min}$, and furnace temperature $1050^{\circ} \mathrm{C}$. The photomultiplier tube voltage was set at $750 \mathrm{~V}$, and the amplification factor was 1 . UV and CLND data were processed using Agilent ChemStation. External calibration was performed at the beginning of each data acquisition sequence with caffeine as standard. Caffeine $(2-4 \mathrm{mg})$ was weighed and dissolved in 0.1\% FA: methanol 90:10 (v/v) to obtain a solution of 1 $\mathrm{mg} / \mathrm{mL}$. Subsequently, $20 \mathrm{~mL}$ of this solution was diluted with 180 $\mathrm{mL}$ of $0.1 \% \mathrm{FA}$ : methanol $90: 10(\mathrm{v} / \mathrm{v})$ to obtain a solution of $0.10 \mathrm{mg} /$ $\mathrm{mL}$, and this solution was further diluted to $0.01 \mathrm{mg} / \mathrm{mL}$, respectively. Caffeine calibration standards were prepared from these standards by diluting with $0.1 \%$ FA: methanol $90: 10(\mathrm{v} / \mathrm{v})$ to obtain caffeine concentrations of 1.0, 2.0, 3.0, 4.0, 5.0, 10, 20, 30, 40 and $50 \mathrm{mg} / \mathrm{mL}$ which were equivalent to the calibration points of $2.9,5.8,8.7,11.5,14.4,28.9,57.7,86.6,115$ and $144 \mathrm{ng}$ of nitrogen per injection. The caffeine curve fit was found to be linear with $\mathrm{R}^{2}>0.999$.

\subsection{Equimolarity}

The equimolarity of nitrogen detection was investigated by analyzing different concentration levels (three levels per compound) of certified reference standard solutions of selected compounds using the caffeine calibration. All analyses were performed in duplicate. Equimolarity was calculated in the concentration level of approximately $20-80 \mathrm{ng}$ of nitrogen per injection, depending on the nitrogen content of the compound. Equimolarity was reported as an average of calculated equimolarities at the different concentration levels.

\section{Results and discussion}

Table 1 shows the $N$-equimolarity of chemiluminescence nitrogen detection for ten fentanyl derivatives and U-47700 by the present LC-CLND method. The grand mean(range) equimolarity of the means of the eleven substances was $96.4 \%$ (91-101\%). Within the nitrogen range indicated in the table, the equimolarity showed no concentration dependence.

Seized samples containing furanylfentanyl, carfentanil and U-47700 were quantified by the caffeine-calibrated LC-CLND method described above. These drugs were identified by high resolution mass spectrometry and, initially by NMR spectroscopy,

Table 1

Equimolarity of nitrogen detection for fentanyl derivatives and U-47700 by LC-CLND.

\begin{tabular}{|c|c|c|c|c|}
\hline Compound & Retention time (min) & Mean equimolarity (\%) & Range ng N/inj. & Equimolarity range (\%) \\
\hline Norfentanyl & 8.86 & 96 & 24-104 & $95.0-96.5$ \\
\hline Remifentanil & 10.95 & 95 & $15-71$ & $94.7-95.7$ \\
\hline U-47700 & 12.35 & 97 & $18-84$ & $96.5-99.2$ \\
\hline Fentanyl & 12.51 & 96 & $16-79$ & $94.8-98.7$ \\
\hline Furanylfentanyl & 12.74 & 98 & $15-70$ & $94.1-99.2$ \\
\hline$\alpha$-Methylfentanyl & 12.79 & 98 & $14-72$ & $89.0-104.0$ \\
\hline para-Fluorofentanyl & 12.89 & 101 & $15-77$ & $97.2-103.7$ \\
\hline trans-3-Methylfentanyl & 13.04 & 91 & $16-90$ & $83.4-95.4$ \\
\hline cis-3-Methylfentanyl & 13.07 & 93 & $16-73$ & $91.9-99.0$ \\
\hline Carfentanil & 13.11 & 98 & $15-70$ & $93.1-100.5$ \\
\hline Sufentanil & 13.50 & 97 & $13-65$ & $95.4-98.4$ \\
\hline
\end{tabular}

a Three concentration levels within the ng/ $\mathrm{N}$ range indicated were analysed in duplicate. 
without other illicit drug findings prior to submitting the samples for quantification by LC-CLND. However, the DAD signal was used to assess the peak purity for CLND calculations, applying a DAD peak purity criterion of $99 \%$ as well as visual inspection. The expanded uncertainty of measurement, calculated as shown before [5], was always $<20 \%$ as the systematic error component was low.

The furanylfentanyl samples, seized between December 2016 and November 2018 by the customs or police, consisted of 112 powdery samples with a mean (median, range) hydrochloride purity of $13 \%$ ( $4.9 \%, 0.08-100 \%)$. Table 2 describes the purity distribution of the furanylfentanyl samples showing a distinctly bipartite nature of low (lower than 9\%) and high (higher than 60\%) purity samples. The majority of the samples were of low purity, and they originated from small 1-10g batches that obviously were intended for personal use on the Finnish market with limited demand for the product.

The carfentanil samples, seized in August and December 2017 by the police, consisted of eight brownish sticky samples with a mean (median, range) hydrochloride purity of $0.064 \%(0.063 \%$, $0.052-0.092 \%)$.

The U-47700 samples, seized between December 2016 and August 2017 by the police and customs, consisted of seven powdery samples with a mean (median, range) hydrochloride purity of $89.0 \%$ (100\%, $51-100 \%)$.

The limitations of the LC-CLND method include only moderate chromatographic resolution and the requirement of a nitrogen atom in the analyte molecule. It is acknowledged that any DAD peak purity algorithm can only confirm the presence of impurities and never prove absolutely that the peak is pure. The CLND response is sensitive to the actual nitrogen configuration for compounds containing adjacent nitrogen atoms [6]. However, these limitations did not negatively affect the presented analysis, because all the studied drugs were nitrogenous and there were no interfering signals in the relevant chromatographic region. The common adulterants caffeine and paracetamol, for instance, eluted much earlier than the opioids investigated. Clearly, the method is amenable to even more general quantification of synthetic opioids.

As stated in the European Drug Report 2019 by the European Monitoring Centre for Drugs and Drug Addiction (EMCDDA), new synthetic opioids pose a serious threat to individual and public health, while fentanyl derivatives make up the majority of the 49 new opioids monitored by the EMCDDA [7]. The present analytical approach meets the requirements posed by the rapidly changing illicit drug scene for instant quantification and valuation of drug seizures. Our future studies will focus on the development of parallel drug analysis by CLND and high resolution mass spectrometry.
Table 2

Purity distribution of 112 seized furanylfentanyl samples.

\begin{tabular}{ll}
\hline Purity as $\mathrm{HCl} \%$ & $\mathrm{~N}$ \\
\hline $0-0.99$ & 1 \\
$1.0-1.9$ & 1 \\
$2.0-2.9$ & 32 \\
$3.0-3.9$ & 17 \\
$4.0-4.9$ & 7 \\
$5.0-5.9$ & 25 \\
$6.0-6.9$ & 25 \\
$7.0-7.9$ & 10 \\
$8.0-8.9$ & 4 \\
$9.0-59$ & 4 \\
$60-69$ & 1 \\
$70-79$ & 0 \\
$80-89$ & 5 \\
$90-100$ & 5 \\
\hline
\end{tabular}

\section{CRediT authorship contribution statement}

Ilpo Rasanen: Methodology, Validation, Formal analysis, Writing - original draft. Marianne Kyber: Resources. Ilmari Szilvay: Resources, Investigation. Janne Rintatalo: Resources. Ilkka Ojanperä: Conceptualization, Methodology, Writing - review \& editing, Supervision.

\section{References}

[1] European Monitoring Centre for Drugs and Drug Addiction, Fentanils and Synthetic Cannabinoids: Driving Greater Complexity Into the Drug Situation. An update from the EU Early Warning System (June 2018), Publications Office of the European Union, Luxembourg, 2018 http://www.emcdda.europa.eu/publications/rapid-communications/fentanils-and-synthetic-cannabinoids-ewsupdate_en. (Accessed 3 October 2019).

[2] P.J. Jannetto, A. Helander, U. Garg, G.C. Janis, B. Goldberger, H. Ketha, The fentanyl epidemic and evolution of fentanyl analogs in the United States and the European Union, Clin. Chem. 65 (2019) 242-253.

[3] A. Skulska, M. Kała, A. Parczewski, Fentanyl and its analogs in the forensic laboratory. Medical and analytical problems, Probl. Forensic Sci. 59 (2004) 127-142.

[4] S. Laks, A. Pelander, E. Vuori, E. Ali-Tolppa, E. Sippola, I. Ojanperä, Analysis of street drugs in seized material without primary reference standards, Anal. Chem. 76 (2004) 7375-7379.

[5] I. Rasanen, M. Kyber, I. Szilvay, J. Rintatalo, I. Ojanperä, Straightforward singlecalibrant quantification of seized designer drugs by liquid chromatographychemiluminescence nitrogen detection, Forensic Sci. Int. 237 (2014) 119-125.

[6] B. Yan, J. Zhao, K. Leopold, B. Zhang, G. Jiang, Structure-dependent response of a chemiluminescence nitrogen detector for organic compounds with adjacent nitrogen atoms connected by a single bond, Anal. Chem. 79 (2007) 718-726.

[7] European Monitoring Centre for Drugs and Drug Addiction, European Drug Report 2019, Trends and Developments, Publications Office of the European Union, Luxembourg, 2019 http://www.emcdda.europa.eu/publications/edr/ trends-developments/2019. (Accessed 3 October 2019). 